\title{
The prevalence and clinical characteristics of cystic fibrosis in South Asian Canadian immigrants
}

\author{
M Mei-Zahav, P Durie, J Zielenski, M Solomon, E Tullis, L-C Tsui, M Corey
}

Arch Dis Child 2005;90:675-679. doi: 10.1136/adc.2003.042614

\begin{abstract}
See end of article for authors' affiliations

Correspondence to:

Dr M Corey, Program in

Population Health

Sciences, The Hospital for

Sick Children, 555

University Avenue,

Toronto, ON, M5G $1 \times 8$

Canada; mary.corey@

sickkids.ca
\end{abstract}

Accepted 28 January 2005

\begin{abstract}
Background: Cystic fibrosis (CF) is considered to be rare among individuals from the Indian subcontinent. Furthermore, affected individuals are reported to experience a more severe clinical course.

Aims: It was hypothesised that CF is under diagnosed in people of South Asian origin and therefore the prevalence may be higher than previously estimated.

Methods: The prevalence of CF in the South Asian and in the general population living in the same geographic region (Metropolitan Toronto) were compared between 1996 and 2001 . Population data were obtained from the Canadian census survey. CF phenotype and genotype data were obtained from the Toronto CF database.

Results: Among 381 patients with CF, 15 were of South Asian descent. The age related prevalence of CF among the South Asian and general populations was: $0-14$ years, 1:9200 versus 1:6600; 15-24 years, 1:13 200 versus 1:7600; older than 25 years, 1:56 600 versus 1:12 400. Age at diagnosis, duration and severity of symptoms at diagnosis, current nutritional status, and $\mathrm{FEV}_{1}$ were similar in the two groups. While not significant, $\mathrm{FEV}_{1}$ tended to be lower (48\% versus $57 \%$ predicted) among adult South Asians, compared to the general CF population. Also, the percentage with pancreatic sufficiency was higher $(27 \%$ versus $16 \%$ ) and the frequency of $\Delta \mathrm{F} 508$ allele was lower (50\% versus $65.1 \%$ ).

Conclusions: These data suggest that the prevalence and natural history of CF in South Asians is similar to that among individuals of European origin. The relatively lower prevalence among older South Asians may reflect an improving recognition of CF in this ethnic subgroup.
\end{abstract}

W hile cystic fibrosis (CF) is the most common fatal inherited disease in the European Caucasian population, it is considered to be rare among individuals from other ethnic groups, including those from the Indian subcontinent. Several reports have described CF in the Indian subcontinent population, ${ }^{1-7}$ as well as in individuals from the same ethnic origin, who immigrated to other countries. ${ }^{8-12}$ These reports estimate the incidence of $\mathrm{CF}$ in this ethnic group to be between 1:10 000 and 1:40 $750 .^{811}$

$\Delta \mathrm{F} 508$, the most common genetic mutation among $\mathrm{CF}$ patients of European origin and in the global CF population, appears to be less common in CF patients of South Asian origin. ${ }^{67^{9-12}}$ Also, patients with CF from the Indian subcontinent have been reported to experience a more severe clinical course than age matched Caucasian children. ${ }^{10}$ However, it is unclear whether the natural course of the disease is more severe, or whether other factors including diagnostic, social, and environmental factors adversely affect the clinical course or its reporting.

Since South Asians are considered to be partially of Caucasian origin, we hypothesised that the prevalence of CF in this ethnic group is higher than previously estimated. To test this hypothesis, the age related prevalence of CF in a South Asian population was compared with the general population living in the same geographic region. We also compared the genotypes, presentation at diagnosis, and natural history of the disease in the two groups.

\section{PATIENTS AND METHODS \\ Patients}

Patients with CF living in Toronto and attending one of two specialised CF clinics (paediatric and adult) in the period 1996-2001 were selected for the study. The diagnosis of CF was based on sweat chloride levels $(>60 \mathrm{mEq} / \mathrm{l})$ and/or two identified CF mutations, as well as characteristic symptoms of CF. For patients with equivocal results, nasal potential difference testing was used to confirm the diagnosis of CF.

We used the most recent Statistics Canada census (1996) estimates of the general and the South Asian population in the Metropolitan Toronto area. ${ }^{13}$ Statistics Canada census (1996) defines all individuals of Indian, Pakistani, Punjabi, and Sri Lankan origin as South Asian. CF patients of South Asian origin were identified using our CF database, hospital records, and by direct questioning. The prevalence of CF in the general and South Asian population was calculated using our database and the Statistics Canada 1996 census data.

We utilised the Metropolitan Toronto area, because the vast majority of South Asians residing in the Province of Ontario live in this area. Furthermore, all South Asian CF patients attending the Toronto CF clinics were living in Metropolitan Toronto.

Use of the database information for the analyses in this study was approved by the institutional human ethics committees.

\section{Clinical characteristics}

All clinical information was obtained from the patient CF database. We assessed the clinical features at presentation including age at diagnosis, nutritional status, pancreatic function, and duration and severity of respiratory and gastrointestinal symptoms prior to diagnosis. Symptoms were considered to be severe if the patient required hospitalisation or had a history of pneumonia, severe functional impairment, or marked failure to thrive. Chronic cough, repeated infections, poor growth, and other symptoms leading to the CF diagnosis but not requiring hospitalisation were defined as moderate symptoms. We also recorded the most recent $\mathrm{FEV}_{1}$ and nutritional status. Z-scores for height, weight, and body mass index (BMI) were computed from the 2000 CDC growth charts. ${ }^{14}$ Nutritional status was 
Table 1 Prevalence of CF among South Asians and the general population living in Metropolitan Toronto

\begin{tabular}{|c|c|c|c|c|c|c|c|}
\hline \multirow[b]{2}{*}{ Age (years) } & \multicolumn{3}{|c|}{ South Asians } & \multicolumn{3}{|c|}{ General population } & \multirow[b]{2}{*}{$p$ value } \\
\hline & $\mathrm{CF}$ & Population & Prevalence & CF & Population & Prevalence & \\
\hline $0-14$ & 9 & 82921 & $1: 9200$ & 130 & 858155 & $1: 6600$ & 0.33 \\
\hline $15-24$ & 4 & 52858 & $1: 13200$ & 73 & 553370 & $1: 7600$ & 0.27 \\
\hline $25-44^{*}$ & 2 & 113250 & $1: 56600$ & & & & $<0.001$ \\
\hline $25-54^{*}$ & & & & 163 & 2021530 & $1: 12400$ & \\
\hline
\end{tabular}

*The difference in adult age groups reflects different adult age categories in Statistics Canada data for the general and South Asian populations. Since the oldest CF patient of South Asian descent was 35 , the difference in prevalence over age 25 is even greater than that presented in the table.

characterised as the percentage of ideal body weight. Ideal weight was computed as the weight corresponding to the same $\mathrm{z}$-score as the height $\mathrm{z}$-score for that patient. We analysed the clinical manifestations of the paediatric $(<18$ years) and adult ( $>18$ years) CF patients separately.

\section{Genotype analysis}

Genomic DNA was screened by allele specific oligonucleotide hybridisation. Extensive mutation analysis was then performed on DNA from patients with undefined mutations using PCR based multiplex heteroduplex analysis in an MDE gel matrix, followed by direct DNA sequencing. This method is estimated to identify up to $95 \%$ of all known CFTR gene mutations. ${ }^{15}$ The poly-thymidine tract $(5 \mathrm{~T}, 7 \mathrm{~T}$, or $9 \mathrm{~T})$ in the acceptor splice site of intron 8 was also characterised.

\section{Statistical analysis}

Fisher's exact test was used to compare proportions for categorical variables. Significance of difference in age at diagnosis was assessed by the Mann-Whitney test. Student's $t$ test was used to compare mean values for other continuous variables.

Results are given as mean and SD or median and range, as appropriate. Multiple regression analysis was used to adjust for different age distribution in comparing $\mathrm{FEV}_{1}$ and percentage of ideal weight between the two groups. A p value of less than 0.05 was considered significant.

\section{RESULTS}

\section{Prevalence}

Between 1996 and 2001, 381 patients with CF were living in the Metropolitan Toronto Area. Fifteen (3.9\%) patients were of South Asian descent, including 11 Indian, two Sri Lankan, and two of Pakistani descent. According to Statistics Canada, 1996 Census, the population of Metropolitan Toronto was 4232 905. The South Asian population of 329840 accounted for $7.8 \%$ of the total population.

The 1996 census data subdivided the population into specific age groups. Therefore, we used the same age groups to compare the age related prevalence of CF in the general population and in the South Asian population. The age specific prevalence of cystic fibrosis in the two groups is shown in table 1 . Overall CF was $28 \%$ less prevalent in South Asians under 15 years of age, than in the general population ( $1: 9200$ versus $1: 6600, p=0.33$ ). However, the difference in prevalence between the two groups became more pronounced at an older age, and in those older than 25 years the difference in prevalence was highly significant $(\mathrm{p}<0.001)$.

In order to minimise bias due to age differences, subsequent comparisons of clinical features were limited to patients aged 35 years or younger, excluding 57 older patients in the general CF population.

\section{Clinical features at diagnosis}

As shown in table 2, the median age at diagnosis in the South Asian population was not different from the general CF population. Similarly, there was no significant difference in the proportion of patients with prolonged respiratory or gastrointestinal symptoms ( $>6$ months) prior to diagnosis between the two groups. The severity of respiratory and gastrointestinal symptoms at diagnosis was also not different in the groups. However, there was evidence of poorer weight expressed as a percentage of ideal weight in the South Asian patients, for the reduced sample with measurements within one year of diagnosis $(90 \pm 14, \mathrm{n}=11$ versus $100 \pm 14$, $\mathrm{n}=275, \mathrm{p}=0.02$ ). While pancreatic sufficiency (PS) was more common in the South Asian CF population (27\% versus $16 \%)$ the difference was not statistically significant. There was no difference in the mean sweat chloride levels at diagnosis. Seven PS patients (one South Asian) ranging in age from 2 to 35 years had sweat chloride values below the classic diagnostic cut-off of $60 \mathrm{mmol} / \mathrm{l}$. The South Asian patient was a 19 year old girl with the $3849+10 \mathrm{kbC} \rightarrow \mathrm{T}$ mutation known to be associated with variable sweat chloride. Her other mutation was unidentified, but her nasal potential difference profile confirmed CF. The other six patients all had two CF mutations identified. Two were homozygous for rare mutations (1868A $>\mathrm{G}$ and $\mathrm{Dl} 152 \mathrm{H})$ and four were heterozygous for $\Delta \mathrm{F} 508(\mathrm{R} 117 \mathrm{H} / 7 \mathrm{~T}(2), \mathrm{R} 117 \mathrm{H} / 5 \mathrm{~T}$, 5T). The patients with R117H/7T, 5T, and homozygous D1152H all had nasal potential difference testing which confirmed CF.

\section{Most recent clinical features}

The mean age of the South Asian CF population was younger than the general CF population (table 2). Children 0-4 years represent $27 \%$ of all South Asian CF versus $7 \%$ in the general CF population. Forty four per cent of the CF patients in the general population were 25 years or older, whereas only two South Asian patients (13\%) were older than 25 years.

South Asian patients tended to weigh less and be shorter but the differences were not significant. Weight, expressed as a percentage of ideal weight for height was normal on average in both groups (table 2). However, using percentage of ideal weight of less than $90 \%$ as an indicator of malnutrition, $27 \%$ of the general CF population and 33\% of the South Asians were malnourished. Regression analysis of percentage of ideal weight versus age showed no age dependent differences between the groups.

As shown in fig 1 , mean $\mathrm{FEV}_{1}$ (\% predicted for age and sex) was similar in the two groups $(64 \pm 24 \%$ in South Asians versus $67 \pm 29 \%$ in the general CF population). Mean $\mathrm{FEV}_{1}$ in the paediatric South Asian group (76 $\pm 17 \%$ ) was very similar to the general population of CF patients $(78 \pm 25 \%)$. However, mean $\mathrm{FEV}_{1}$ tended to be lower in the adult South Asians compared with the adult general CF population. Using regression analysis to account for the age difference, $\mathrm{FEV}_{1}$ was found to be $7 \%$ lower in South Asians than in the general population, but this difference was not significant $(\mathrm{p}=0.4)$. Pseudomonas aeruginosa was isolated from $67 \%$ of the South Asians and from $61 \%$ of the general CF population $(p=0.6)$. Eleven per cent of patients in the general CF population and $13 \%$ of the South Asians died during the five year study period. 


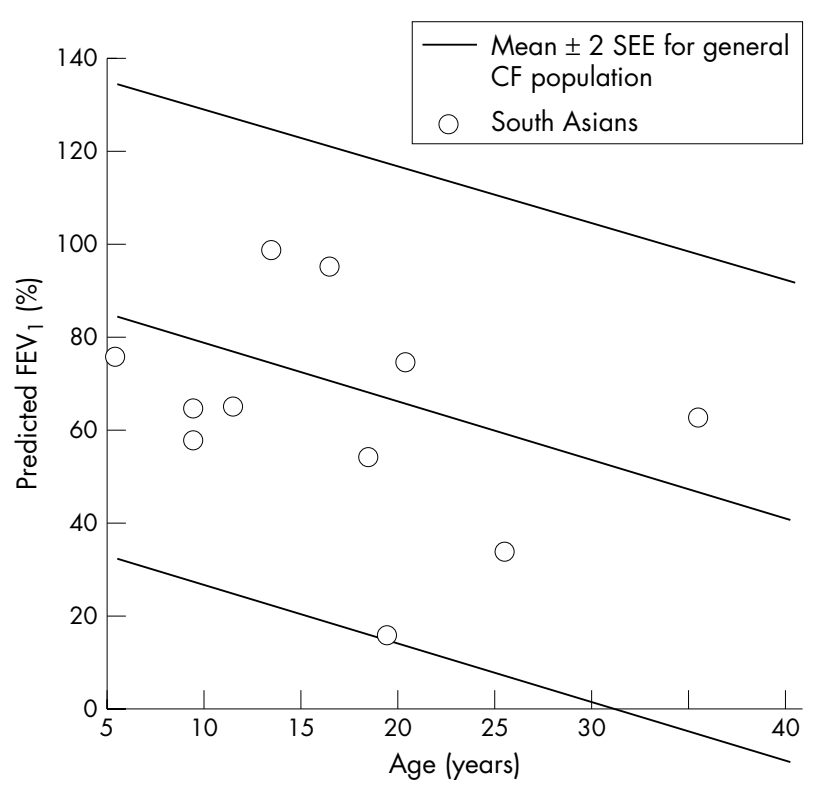

Figure 1 Pulmonary functions in individual CF patients of South Asian origin compared with the general CF population showing $F E V_{1}$ in CF South Asian patients to be within the $\mathrm{FEV}_{1}$ range (mean \pm SEE) for the age related general CF population. SEE, standard error of estimate.

\section{Genetics}

Extensive mutation analysis was performed in 301 (93\%) patients under age 36, including 13 South Asians (table 3). CFTR gene mutations were identified on both alleles of 248 $(86 \%)$ of the general population and eight $(61.5 \%)$ South Asian patients. Forty three per cent of the general population and $46 \%$ of the South Asians were found to be homozygous for $\Delta \mathrm{F} 508$. However, the overall frequency of $\Delta \mathrm{F} 508$ allele was lower in South Asians (50\% versus 65.1\%) than in the general CF population. Other mutations identified in the South Asian population are listed in table 3. Extensive mutation analysis failed to identify mutations in $26.9 \%$ alleles in South Asians and in $8.2 \%$ of alleles in the general CF population.

\section{DISCUSSION}

$\mathrm{CF}$ is considered to be rare among individuals of nonEuropean Caucasian origin, including those whose ethnicity originates from the Indian subcontinent. Since the first description of the existence of CF in a South Asian patient in $1968,{ }^{3}$ several case series have attempted to define the prevalence and clinical characteristics of $\mathrm{CF}$ in patients of this ethnic origin. While prevalence estimates of CF in this ethnic group are not clearly defined, several studies have suggested that it is considerably lower than in Caucasians of European origin. In a survey of 116 CF centres in the United States, Powers and colleagues ${ }^{11}$ found only 20 patients of Asian Indian descent. Based on the estimation of the Asian Indian population in the 1990 US census report, an incidence of 1:40 750 was suggested. However, the authors speculated that they may have greatly underestimated the real incidence of CF in individuals from this ethnic group. Since all 20 patients in this survey were diagnosed during the last decade, older patients with CF may have been missed. Goodchild and colleagues $^{8}$ identified three children with CF of Pakistani origin in the West Midland region of England. A questionnaire, sent to all paediatricians in this area, failed to find any other South Asians with CF. A population survey estimated the South Asian population in this region to be approximately 30000 , which suggested an incidence of 1:10 000. They hypothesised that most South Asians are Caucasian by race, and therefore the incidence of CF in South Asians might be even higher than their population based estimation.

Curtis and colleagues ${ }^{12}$ calculated the incidence of CF based on limited CFTR mutation analysis of DNA from unrelated, unaffected Indians who donated blood in Bombay. $\Delta$ F508 mutation was not detected in DNA from 400 individuals, while none of the exon 11 mutations G551D, R553X, or S549 were identified in DNA from 200 of these patients. Since very few mutations were screened and the relative frequency of the common CFTR gene mutations in the South Asians has not been determined, this report may well have underestimated the incidence of CF carrier status in this population.

While the US survey found only 20 patients of South Asian descent in the whole US population (248 709 873),, ${ }^{11}$ we

\begin{tabular}{|c|c|c|c|}
\hline Clinical manifestations & $\begin{array}{l}\text { South Asian CF } \\
\text { patients }(n=15)\end{array}$ & $\begin{array}{l}\text { General CF patients } \\
(n=309)\end{array}$ & p value \\
\hline \multicolumn{4}{|l|}{ Symptoms before diagnosis } \\
\hline Respiratory, > $>6 \mathrm{~m} \%$ & 33 & 32 & $0.9 \ddagger$ \\
\hline Gastrointestinal, > $>6 \mathrm{~m} \%$ & 13 & 30 & $0.2 \ddagger$ \\
\hline \multicolumn{4}{|l|}{ At diagnosis } \\
\hline $\begin{array}{l}\text { Median age (range) } \\
\text { Pancreatic sufficiency \% }\end{array}$ & $\begin{array}{l}6 m(0-19 y) \\
27\end{array}$ & $\begin{array}{l}7 m(0-35 y) \\
16\end{array}$ & $\begin{array}{l}0.4^{*} \\
0.14 \dagger\end{array}$ \\
\hline $\begin{array}{l}\text { Moderate-severe respiratory } \\
\text { symptoms \% }\end{array}$ & 27 & 33 & $0.8 \ddagger$ \\
\hline $\begin{array}{l}\text { Moderate-severe gastrointestinal } \\
\text { symptoms } \%\end{array}$ & 53 & 58 & $0.8 \ddagger$ \\
\hline $\begin{array}{l}\text { Sweat chloride concentration } \\
\mathrm{mmol} / \mathrm{l} \text {, median (range) }\end{array}$ & $95(47-126)$ & $101(30-166)$ & $0.2 \dagger$ \\
\hline \multicolumn{4}{|l|}{ At most recent visit } \\
\hline Age (years) & $12.8 \pm 10.1$ & $18.4 \pm 10.0$ & $0.04 \dagger$ \\
\hline Height z-score & $-0.8 \pm 0.9$ & $-0.4 \pm 1.0$ & $0.10 \dagger$ \\
\hline Weight $z$-score & $-0.9 \pm 1.4$ & $-0.6 \pm 1.3$ & $0.3+$ \\
\hline BMl z-score & $-0.5 \pm 1.3$ & $-0.5 \pm 1.3$ & $0.9 \dagger$ \\
\hline Weight, $\%$ of ideal & $101 \pm 20$ & $99 \pm 14$ & $0.6 \dagger$ \\
\hline $\mathrm{FEV}_{1}, \%$ predicted & $64 \pm 24$ & $67 \pm 29$ & $0.8 \dagger$ \\
\hline Pseudomonas aeruginosa, $\%$ & $67^{-5}$ & 61 & $0.6 \ddagger$ \\
\hline \multicolumn{4}{|l|}{$\begin{array}{l}\text { *Mann-Whitney test. } \\
\text { †Student's } t \text { test. } \\
\text { fFischer's exact test. }\end{array}$} \\
\hline
\end{tabular}




\section{What is already known on this topic}

- CF is rare in populations not of European Caucasian origin

- More severe disease has been reported in South Asian CF patients

- $\Delta \mathrm{F} 508$, the most common mutation in Caucasians, is less prevalent in South Asians

identified 15 children of the same ethnic origin in a population that was 50 -fold smaller. In fact, the prevalence of CF among young South Asians living in Metropolitan Toronto was higher than all other previous estimates and similar to that observed in the age matched general population. A much lower prevalence of CF among South Asian adults living in the same geographic region suggests that South Asian patients born with CF two or more decades ago either died or remain undiagnosed. This observation leads us to speculate that previously there was inadequate awareness of the existence of CF among individuals of South Asian origin. Consequently, only the more severe cases may have been diagnosed. This might explain the more severe clinical course described in previous reports, ${ }^{811}$ and the somewhat lower $\mathrm{FEV}_{1}$ in our adult South Asian CF population. With larger numbers, some of the clinical differences we explored may have been significant, but the magnitude of difference is still much smaller than previously reported.

In a recent series of 17 patients from North India the mean duration of symptoms prior to diagnosis was $4.05 \pm$ 2.1 years, and mean age at diagnosis was $4.78 \pm 3.42$ years. ${ }^{5}$ It is noteworthy that three patients $(18 \%)$ in that report were diagnosed at postmortem examination. In contrast to all published reports, we found no evidence of delayed diagnosis of CF among our patients of South Asian origin. Furthermore, age at diagnosis, duration of symptoms prior to diagnosis, and severity of symptoms at diagnosis were quite similar to the general CF population. Taken together, this information suggests that physicians practicing in our region now have appropriate awareness of the existence of this disease among children of South Asian origin. Furthermore, with prompt diagnosis and therapy the clinical course among CF children of South Asian origin is no different to the general CF population. Socioeconomic status may have an impact on access to medical services among immigrant families. However, universal access to medical care and specialised CF centres in Canada

\section{What this study adds}

- Prevalence and clinical course of CF in children of South Asian origin is similar to that in the general Toronto population

- Previous reports reflect inadequate awareness of $\mathrm{CF}$ in this ethnic group

- The prevalence of $\triangle \mathrm{F} 508$ is confirmed to be lower in South Asians than other Caucasian groups

would make this issue less likely in our study than in other reports.

The most common mutation in the Caucasian CF population, $\Delta \mathrm{F} 508$, accounts for $66 \%$ of CF chromosomes on a worldwide basis. ${ }^{16}$ Previous reports have suggested a lower prevalence of $\Delta \mathrm{F} 508$ in patients from the Indian subcontinent. A review of all genotyped South Asian patients, reported in published articles ${ }^{67-12}$ and together with those reported in the current series, shows that $\Delta \mathrm{F} 508$ was identified in 66 of $162(41 \%)$ alleles, which appears to be considerably lower than the reported frequency of $66 \%$ in the worldwide CF population. Furthermore, extensive mutation analysis failed to identify CFTR gene mutations in $26.9 \%$ of the South Asian alleles in our study. We found several rare mutations, all but one of which have been identified in patients originating from the Indian subcontinent or neighbouring regions. Nevertheless, $\Delta$ F508 remained the most common CFTR gene mutation in this South Asian population and the prevalence was only slightly less than that observed in our general CF population. This observation supports the hypothesis that immigration patterns between Europe and the Indian subcontinent are contributing to the evolution of $\mathrm{CF}$ in the Indian subcontinent.

The higher than expected frequency of PS patients and the lower mutation detection among South Asians may reflect a higher frequency of rare mild variants or intronic mutations not specifically included in our current screening methods. In addition, the protocol is less efficient in detecting homozygotes for point mutations, so that if some of the SA patients are homozygous for rare mutation(s) they could be undetected.

In summary, we show for the first time that the prevalence and clinical presentation of CF in the young South Asians are similar to a general CF population residing in the same geographic region. Our observations also provide indirect evidence of an improvement in knowledge among physicians of the existence of CF among individuals of South Asian origin.

Table 3 CFTR gene mutations among CF patients of South Asian origin and all patients living in the same geographic region in the CF population

\begin{tabular}{|c|c|c|c|c|c|}
\hline \multirow[b]{2}{*}{ Mutation } & \multicolumn{2}{|c|}{$\begin{array}{l}\text { South Asian CF population } \\
\text { (number, \% of total alleles) }\end{array}$} & \multirow[b]{2}{*}{ Mutation } & \multicolumn{2}{|c|}{$\begin{array}{l}\text { General CF population } \\
\text { (number, \% of total alleles) }\end{array}$} \\
\hline & No. identified & $\%$ of alleles & & No. identified & $\%$ of alleles \\
\hline$\Delta \mathrm{F} 508$ & 13 & 50 & $\Delta \mathrm{F} 508$ & 375 & 65.1 \\
\hline L218X & 2 & 7.7 & W1282X & 16 & 2.8 \\
\hline $1525-1 G \rightarrow A$ & 1 & 3.8 & G551D & 15 & 2.6 \\
\hline S549N & 1 & 3.8 & G542X & 10 & 1.7 \\
\hline $3849+10 \mathrm{kbC} \rightarrow \mathrm{T}$ & 1 & 3.8 & $621+1 G \rightarrow T$ & 10 & 1.7 \\
\hline \multirow{3}{*}{ V392G } & 1 & 3.8 & R117H & 7 & 1.2 \\
\hline & & & N1303K & 7 & 1.2 \\
\hline & & & 49 others $(<1 \%)$ & 89 & 16.4 \\
\hline Unidentified & 7 & 26.9 & Unidentified & 47 & 8.2 \\
\hline
\end{tabular}




\section{Authors' affiliations}

M Mei-Zahav, M Solomon, Division of Respiratory Medicine, The

Hospital for Sick Children, Toronto, Ontario, Canada

E Tullis, Division of Respiratory Medicine, St Michael's Hospital, Toronto,

Ontario, Canada

P Durie, Division of Gastroenterology and Nutrition, The Hospital for

Sick Children, Toronto, Ontario, Canada

L-C Tsui, J Zielenski, Program in Genetics and Genomic Biology, The Hospital for Sick Children, Toronto, Ontario, Canada

M Corey, Program in Population Health Sciences, The Hospital for Sick Children, Toronto, Ontario, Canada

Funding: supported, in part, by research grants to $M C, J Z, E T$, and $P D$, from the National Institutes of Health (NIDDK. NIHSCOR 2P50 DK49096-07) and from the Canadian Cystic Fibrosis Foundation

Competing interests: none declared

\section{REFERENCES}

1 Reddy CR, Sita Devi C, Anees AM, et al. Cystic fibrosis of pancreas in India. J Trop Med Hyg 1970;73:59-62.

2 Prasad ML, Misra A, Mathur M, et al. Cystic fibrosis: postmortem report on two cases. Indian Pediatr 1990;27:493-6.
3 Bhakoo ON, Kumar R, Walia BN. Mucoviscidosis of the lung. Report of a case. Indian J Pediatr 1968;35:183-5.

4 Harendra DG, Lakkumar Fernando AJA, Senaka Gunatilleke MDA. Cystic fibrosis in Sri Lanka. Ceylon Med J 1994;39:50-2.

5 Singh M, Prasad R, Kumar L. Cystic fibrosis in North Indian children. Indian J Pediatr 2002;69:627-9.

6 Bhutta ZA, Moattar T, Shah U. Genetic analysis of cystic fibrosis in Pakistan: a preliminary report. J Pakistan Med Assoc 2000;50:217-19.

7 Kabra M, Kabra SK, Ghosh $M$, et al. Is the spectrum of mutations in Indian patients with cystic fibrosis different? Am J Med Gen 2000;93:161-3.

8 Goodchild MC, Insley J, Rushton DI, et al. Cystic fibrosis in three Pakistani children. Arch Dis Child 1974;49:739-41.

9 Schwarz MJ, Super M, Wallis C, et al. Delta 508 testing of the DNA bank of the royal Manchester Children's Hospital. Hum Genet 1990;85:428-30.

10 Bowler IM, Esttlin EJ, Littlewood JM. Cystic fibrosis in Asians. Arch Dis Child 1993;68:120-2.

11 Powers CA, Potter EM, Wessel HU, et al. Cystic fibrosis in Asian Indians. Arch Pediatr Adolesc Med 1996;150:554-5.

12 Curtis A, Richardson RJ, Boohene J, et al. Absence of cystic fibrosis mutations in a large Asian population sample and occurrence of a homozygous S549N mutation in an inbred Pakistani family. J Med Genet 1993;30:164-6.

13 Statistics Canada. Government of Canada, 1996, www.statcan.ca.

14 National Center for Health Statistics. CDC Growth Charts, 2000, www.cdc.gov/growthcharts.

15 Zielenski J, Aznarez I, Onay T, et al. CFTR mutation detection by multiplex heteroduplex (mHET) analysis on MDE gel. Methods Mol Med 2002;70:3-19.

16 Cystic Fibrosis Mutation Data Base. www.genet.sickkids.ca.

\section{Call for papers}

11 th European Forum on Quality Improvement in Health Care

26-28 April 2006, Prague, Czech Republic

Deadline 30 September 2005.

For further information and to submit online go to: www.quality.bmipg.com 